Check for updates

Cite this: RSC Adv., 2017, 7, 40189

\title{
Theoretical studies on the structure and thermochemistry of cyclicparaphenylenediazenes $\uparrow$
}

Received 8th June 2017

Accepted 8th August 2017

DOI: $10.1039 / \mathrm{c} 7 \mathrm{ra06409h}$

rsc.li/rsc-advances

\author{
Mohamad Akbar Ali (D) *a and Mohammad A. Alam (D)*b
}

Cyclicparaphenylenediazenes (CPPDs) have drawn great attention due to their potential applications in molecular electronics and solar energy. However, to date, there have been no detailed structure and thermochemistry investigations on CPPDs. Herein, we used an integrated computational approach aimed at providing reliable structural and thermochemical information on novel CPPDs based photoswitchable molecular rings. The approach involves hybrid density functional theory calculation at the B3LYP/6-31+G(d,p) level coupled with homodesmotic reaction approach to calculate strain energies (SE) and standard enthalpies of formation $\left(\Delta_{\mathrm{f}} \mathrm{H}_{298}^{\circ}\right)$ of all cis and all trans isomers of [ $n$ ]CPPDs ( $n=2$ to 8). The results show that strain energies and $\Delta_{f} H_{298}^{\circ}$ per-unit monomer of all cis-[n]CPPDs ( $n=4$ to 8 ) increase with increasing the numbers of $\mathrm{Ph}-\mathrm{N}=\mathrm{N}$ linkages. However, an opposite trend was observed for all trans-[n]CPPDs ( $n=4$ to 8 ). The results were also compared with carbon nanoring structures i.e., cyclicparaphenyleneacetylenes (CPPAs) and cycloparaphenylenes (CPPs). The calculated highest occupied molecular orbital (HOMO) to the lowest unoccupied molecular orbital (LUMO) energy gaps are in the range of $1.98 \mathrm{eV}$ to $2.36 \mathrm{eV}$, indicating potential material for the construction of solar cells. The reported structures, $\mathrm{SE}, \Delta_{\mathrm{f}} H_{298}^{\circ}$, and electronic properties of CPPDs can be also helpful to synthesize these novel materials.

\section{Introduction}

Nitrogen-doped cyclic oligomers including cyclic azobenzenophanes (CABPs) have received great attention ${ }^{\mathbf{1 , 2}}$ due to their potential applications in semiconductor devices, ${ }^{3}$ highperformance catalytic reactions, ${ }^{4,5}$ Li-ion batteries, ${ }^{6}$ ultracapacitors, optomechanical devices, ${ }^{7-9}$ biochemical applications, ${ }^{10}$ photoswitches in photopharmacology, ${ }^{11-13}$ and molecular motors in drug delivery. ${ }^{\mathbf{1 4 , 1 5}}$ These attractive properties of CABPs are all due to their cis-trans photo and thermal isomerization, and due to their molecular strain. ${ }^{16-19}$

CABPs, in which two, three, and four azobenzene (AB) units are connected by $-\mathrm{CH}_{2}-\mathrm{CH}_{2}-$ and $-\mathrm{CH}_{2}-\mathrm{S}-\mathrm{CH}_{2}-$ chains at the meta and para positions have been studied by various research groups. ${ }^{16,17}$ Nagamani et al. ${ }^{17}$ have reported CABPs, in which two $\mathrm{AB}$ are connected by $-\mathrm{CH}_{2}-\mathrm{CH}_{2}-$ group at the para positions. They suggested trans, trans $(\mathrm{t}, \mathrm{t})$ isomers are more stable than the trans, cis (t,c) and cis, cis (c,c) isomers. In another study, Rau and Lueddecke ${ }^{18}$ have prepared an azobenzenophane (ABP), in

${ }^{a}$ Department of Chemistry, Sejong University, Seoul, 143-747, Republic of Korea. E-mail: akbar256@sejong.ac.kr

${ }^{b}$ Department of Chemistry and Physics, College of Science and Mathematics, Arkansas State University, Jonesboro, AR 72467,USA.E-mail: malam@astate.edu

$\dagger$ Electronic supplementary information (ESI) available: Tables of optimized geometries, vibrational frequencies, ZPEs, thermal correction, entropy for CPPDs. Table of ring diameter of CPPDs, CPPAs, and CPPs and figures showing HOMO, LUMO and HOMO-LUMO gap of CPPDs. See DOI: 10.1039/c7ra06409h which two $\mathrm{AB}$ are connected by $-\mathrm{CH}_{2}-\mathrm{S}-\mathrm{CH}_{2}-$ chains at the para positions. They found photoisomerization of $\mathrm{ABP}$ was based on a rotation/inversion mechanism from the state of $\mathrm{AB}$, which was inhibited due to the ring strain. In 2013, Durgun and Grossman ${ }^{19}$ performed the density functional theory (DFT) calculations on the structure and enthalpies of reaction of cis and trans$[n]$ azobenzenophanes ( $n=2$ to 6 ). In their study, the effect of steric distortion on photoisomerization and thermal stability $[n]$ azobenzenophanes ( $n=2$ to 6$)^{19}$ with $-\mathrm{CH}_{2}$ - linkage were calculated. These CABPs has been suggested for the construction of solar thermal fuel, ${ }^{20}$ and photoswitchable devices. ${ }^{12,13}$

The next challenging target in the research field is another important class of CABPs, so called cyclicparaphenylenediazenes (CPPDs). CPPDs are obtained by connecting phenyldiazene $(\mathrm{Ph}-\mathrm{N}=\mathrm{N}-)$ unit through para linkage as shown in Fig. 1. CPPDs can be constructed by replacing acetylenic bond $(-\mathrm{C} \equiv \mathrm{C}-)$ with an azo group $(-\mathrm{N}=\mathrm{N}-)$ on cyclicparaphenyleneacetylenes (CPPAs) oligomer ${ }^{21,22}$ and can be formed by inserting an azo group between two benzene rings of cycloparaphenylenes (CPPs) $)^{23-25}$ (Fig. 1). Very few theoretical studies have been carried out on CPPDs. ${ }^{19,26}$ As far as we know Durgun and Grossman reported the structure and enthalpies of all cis and all trans isomer of cyclic[6]paraphenylenediazenes ([6] CPPD). ${ }^{19}$ Recently, Van Raden et al. ${ }^{27}$ have synthesized highly strained nitrogen-doped cyclicparaphenylenes i.e., aza[6]CPP. They calculated highest occupied molecular orbital (HOMO) and lowest unoccupied molecular orbital (LUMO) energy gap 
level using hybrid DFT at B3LYP/6-31G(d) level. In another study, Yuan et $a .^{26}$ have predicted the host-guest interaction between [6]CPPD and [7]CPPD with fullerene $\left(\mathrm{C}_{60}\right)$ using hybrid DFT at M06-L and M06-2X levels. They reported the relative stabilities of host-guest interactions between fullerene $\mathrm{C}_{60}$ and [6]CPPD and [7]CPPD by varying nitrogen atoms in the ring.

Over the years, many hypothetical chemical reactions have been proposed in an effort to predict the thermochemistry of organic and inorganic molecules. Since Baeyer's ${ }^{28}$ classic strain theory from 1885 and Bredt's rule almost 100 years ago, strained hydrocarbons have aroused considerable interest to chemists and material scientists. Efforts of chemists to bend and break Bredt's rule have generated a great variety of interesting molecules. Angle strained cyclic oligomer i.e., CPPAs, CPPs, and CPPDs are the important class of strained hydrocarbons that are attractive to both experimental and theoretical chemists. ${ }^{19,22,25}$ Some of these molecules are useful in photovoltaic cells because they have strong electron withdrawing character of the triple bond and their rod-like structure. ${ }^{29}$

The group equivalent method, Westheimer bond angle method, ${ }^{30}$ Dudev ring fragment method, ${ }^{31}$ Wiberg heats of reaction method, isodesmic, ${ }^{32-37}$ connectivity-based hierarchy, ${ }^{38}$ and homodesmotic reaction approaches, etc. ${ }^{21,32,39-41}$ are a few (a)



Lewis

Chem. Soc. Rev. 2015

(c)
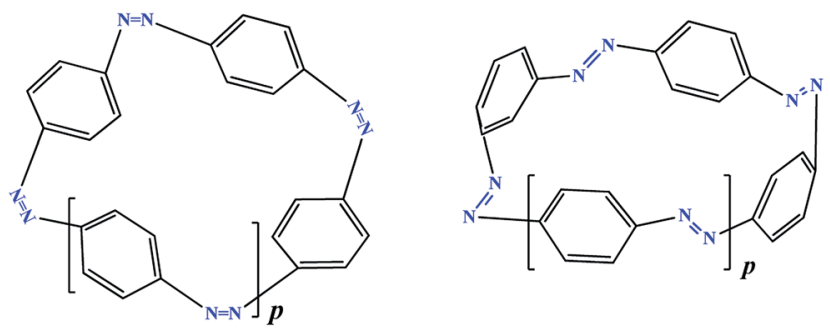

all cis-[n]CPPDs

Chem. Rev. 2006 (b)

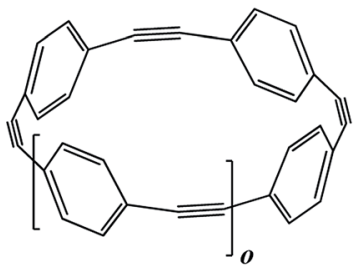

Kawase

all trans -[n]CPPDs
This Work

Fig. 1 Structure of (a) [n]CPPs, where $m(m=n-3)$ represents phenyl $(\mathrm{Ph}-)$ monomer $(\mathrm{b})[n]$ CPPAs, where o $(o=n-3)$ represents $\mathrm{Ph}-$ $\mathrm{C} \equiv \mathrm{C}$ - monomer and (c) [ $n$ ]CPPDs, where $p(p=n-3)$ represents number of $\mathrm{Ph}-\mathrm{N}=\mathrm{N}$ monomer. The all cis isomers of CPPDs are represented as $\left[2_{c}\right]$ CPPD, [3 $]$ ]CPPD, $\left[4_{c}\right]$ CPPD, [5 $\left.{ }_{c}\right]$ CPPD, $\left[6_{c}\right] C P P D$, $\left[7_{\mathrm{C}}\right] \mathrm{CPPD}$, and $\left[8_{\mathrm{C}}\right] \mathrm{CPPD}$ and all trans isomers of CPPDs are represented as $\left[2_{t}\right]$ CPPD, $\left[3_{t}\right]$ CPPD $\left[4_{t}\right] C P P D,\left[5_{t}\right] C P P D,\left[6_{t}\right] C P P D,\left[7_{t}\right] C P P D$, and $\left[8_{\mathrm{t}}\right] \mathrm{CPPD}$. widely used methods in literature for calculating strain energies (SE) and standard enthalpies of formation $\left(\Delta_{\mathrm{f}} \mathrm{H}_{298}^{\circ}\right)$ of cyclic and acyclic molecules. In this paper, we have used similar approaches i.e., isodesmic and homodesmotic reaction schemes coupled with density functional theory to analyze the trends of SE and $\Delta_{\mathrm{f}} H_{298}^{\circ}$ of CPPDs.

To the best of our knowledge, there have been no experimental and theoretical studies on structure, thermochemistry, and electronic properties of all cis and all trans isomers of cyclic $[n]$ paraphenylenediazenes ([n]CPPDs) $(n=2$ to 8$)$. The synthesis of angle-strained $[n]$ CPPDs is highly desirable due to their potential application in $\pi$-conjugated organic materials. In this paper we attempt to quantify this synthetic challenge, by applying an integrated computational strategy aimed at providing reliable structure, molecular orbitals, SE, and $\Delta_{\mathrm{f}} H_{298}^{\circ}$ for all cis and all trans-CPPDs. The SE of highly strained CPPDs and weakly strained CPPDs molecules have a significant impact on their stability and reactivity, were calculated using hybrid density functional methods in combination of homodesmotic reaction approach. ${ }^{39}$ The SE of CPPDs was also compared with its analogous $\pi$-conjugated oligomer (Fig. 1) i.e., CPPs and CPPAs, which have been suggested for the model compounds for carbon nanotube and carbon nanobelt. ${ }^{21,22,25,40}$ To further explore the structure of novel CPPDs and its applications in molecular electronics and in solar energy, we calculated the energies of HOMO, LUMO, and HOMO-LUMO gap.

\section{Theoretical methodology}

The geometrical, energetical, vibrational, and electronic properties of all cis-[n]CPPDs (designated as $\left[n_{\mathrm{c}}\right]$ CPPDs) $(n=2$ to 8$)$ and all trans-[n]CPPDs isomer of $[n]$ CPPDs (designated as $\left[n_{\mathrm{t}}\right]$ CPPDs) ( $n=2$ to 8 ) were performed using hybrid DFT; B3LYP ${ }^{42}$ in conjunction with 6-31+G(d,p) basis set as implemented in the Gaussian 09 (Rev. D.01) and Gaussian 09 (Rev.E.01) program suites. ${ }^{43,44}$ No symmetry constraint was applied during geometry optimization. Optimized geometries and vibrational frequencies are tabulated in the ESI (Tables S1-S4 $\dagger$ ). The nature of all stationary points on the potential energy surface (PES) (minimum) was checked by diagonalizing the corresponding Hessians. The absence of imaginary frequency confirms that the obtained structure corresponds to a true minimum on the potential energy surface. The zero-point energy (ZPE), and thermal correction $\left(\Delta H_{\mathrm{T}}\right)$ were calculated from vibrational frequency analysis. We have chosen the B3LYP model, since it produces reasonably good $\pi$-conjugated structures, and appropriate for the prediction of electronic structure of polycyclic hydrocarbons and their energies. ${ }^{21,27,34,35,40,45-48}$ The combination of $\mathrm{B}^{2} \mathrm{LYP}^{42}$ with $6-31 \mathrm{G}(\mathrm{d})$ and $6-31+\mathrm{G}(\mathrm{d}, \mathrm{p})$ basis sets has been tested by other groups and results were found to be in good agreement with experimental values. ${ }^{21,40,46,48}$ Therefore, we believe the same combination will provide reasonably accurate geometrical parameters and vibrational frequencies for $[n]$ CPPDs.

Some calculations were also carried out using high-level quantum composite Gaussian-4 (G4) method $^{49}$ as implemented in the Gaussian 09 (Rev. D.01) ${ }^{43}$ and Gaussian 09 
(Rev.E.01) ${ }^{44}$ program suites. The G4 theory ${ }^{49}$ is the fourth in the Gaussian- $n$ series of quantum chemical methods, which is based on geometry optimization as well vibrational analysis of molecules at the B3LYP/6-31G(2df,p). This calculation is followed by a series of single-point energy calculations with higher level of theory: $\operatorname{CCSD}(\mathrm{T}, \mathrm{FC}) / 6-31 \mathrm{G}(\mathrm{d}), \operatorname{MP} 4$ (FC)/6-31G(d), MP4(FC)/6-31+G(d), MP4 (FC)/6-31G(2df,p), and MP2(FU)/ G3LargeXP. ${ }^{49}$ The G4 method produces approximate energy accuracy of $\pm 1 \mathrm{kcal} \mathrm{mol}^{-1}$. $^{49}$

The calculation of SE and $\Delta_{\mathrm{f}} H_{298}^{\circ}$ of $[n]$ CPPDs were carried out using similar homodesmotic reaction approach ${ }^{39}$ as discussed in previous works. ${ }^{21,24}$ The SE and $\Delta_{\mathrm{f}} H_{298}^{\circ}$ of a hypothetical isodesmic or homodesmotic reaction schemes of unknown molecule A of reaction type $n \mathrm{~A}+m \mathrm{~B} \rightarrow r \mathrm{C}+s \mathrm{D}$ were calculated using;

$$
\text { Strain energy }=\sum \Delta E_{0 \mathrm{~K}}^{\text {products }}-\sum \Delta E_{0 \mathrm{~K}}^{\text {reactants }}
$$

where, $\Delta E_{0 \mathrm{~K}}^{\text {products }}$ and $\Delta E_{0 \mathrm{~K}}^{\text {reactants }}$ are the energy differences for products and reactants at $0 \mathrm{~K}$.

$$
n \Delta_{\mathrm{f}} H_{298}^{\circ}(\mathrm{A})=r \Delta_{\mathrm{f}} H_{298}^{\circ}(\mathrm{C})+s \Delta_{\mathrm{f}} H_{298}^{\circ}(\mathrm{D})-m \Delta_{\mathrm{f}} H_{298}^{\circ}(\mathrm{B})-\Delta H_{298}^{\mathrm{rxn}}
$$

where, $\Delta_{\mathrm{f}} H_{298}^{\circ}(\mathrm{B}), \Delta_{\mathrm{f}} H_{298}^{\circ}(\mathrm{C})$, and $\Delta_{\mathrm{f}} H_{298}^{\circ}(\mathrm{D})$ are enthalpies of formation of species $\mathrm{B}, \mathrm{C}$, and $\mathrm{D}$, respectively and $\Delta H_{298}^{\mathrm{rxn}}$ is the enthalpies of reaction for reaction $n \mathrm{~A}+m \mathrm{~B} \rightarrow r \mathrm{C}+s \mathrm{D}$.
All the optimized geometrical parameters and vibrational frequencies are given in the ESI. $\uparrow$ Strain energies, enthalpies of reaction, enthalpies of formation, and enthalpies of combustion are expressed in $\mathrm{kJ} \mathrm{mol}^{-1}$, vibrational frequencies in $\mathrm{cm}^{-1}$ and HOMO, LUMO, and HOMO-LUMO gap energies in eV.

\section{Results and discussion}

\subsection{Structure of $[n]$ CPPDs}

Before discussing thermochemistry and electronic properties, it is necessary to examine the molecular geometries of CPPDs, since they are closely related to physical and chemical properties. Structure of all cis- $\left[n_{\mathrm{c}}\right]$ CPPDs $(n=2$ to 8$)$ and all trans- $\left[n_{\mathrm{t}}\right]$ CPPDs ( $n=2$ to 8 ) were optimized using at B3LYP/6-31+G(d,p) level of theory. Optimized structures of all cis and all transCPPDs are shown in Fig. 2 and 3, respectively. To find out the different conformations of all trans-CPPDs and all cis-CPPDs, we have carried out many geometry optimizations. For example, in the case of all trans-[6 $\left.6_{t}\right]$ CPPD, we started different orientation of phenyl group in $\left[6_{t}\right]$ CPPD and in all cases, we have obtained a stable circular structure as shown in the ESI Fig. S1. $\dagger$ Therefore, we believe that the possibilities of other stable structures are negligible for all trans-CPPDs. However, in case of all-cis CPPDs, we have found the different conformation of $\left[6_{c}\right] \mathrm{CPPD}$, $\left[7_{c}\right]$ CPPD, and $\left[8_{c}\right]$ CPPD as shown in the Fig. 2. The mix



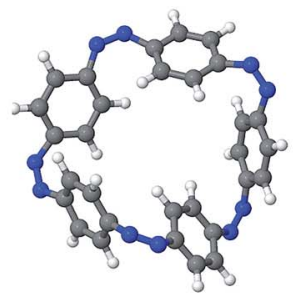

$[5 \mathrm{c}] \mathrm{CPPD}$



$\left[6_{c}\right] \mathrm{CPPD}_{1}$

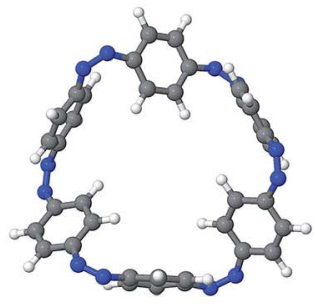

$\left[6_{c}\right] \mathrm{CPPD}_{2}$

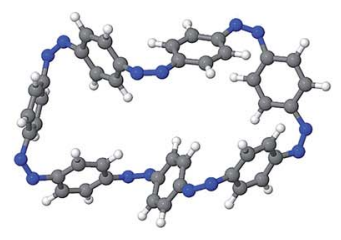

$\left[7_{\mathrm{c}}\right] \mathrm{CPPD}_{1}$

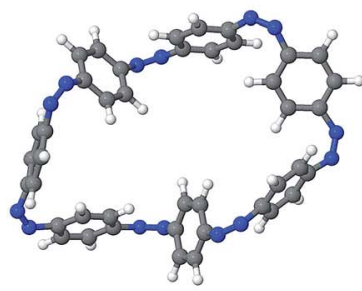

$\left[7_{\mathrm{c}}\right] \mathrm{CPPD}_{2}$

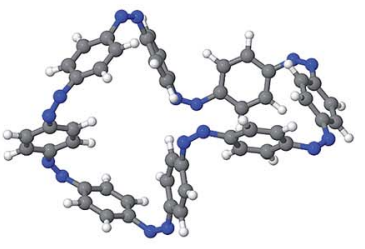

$\left[8_{\mathrm{c}}\right] \mathrm{CPPD}_{1}$

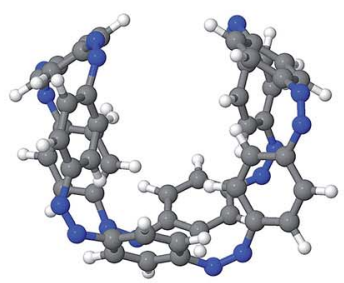

$\left[8_{\mathrm{c}}\right] \mathrm{CPPD}_{2}$

Fig. 2 Optimized structures of all cis-[n]CPPDs $(n=2$ to 8$)$ obtained using B3LYP/6-31+G(d,p) level of theory. The hydrogen, carbon, and nitrogen atoms are indicated by white, grey, and blue spheres, respectively. The different conformation of $\left[6_{c}\right] C P P D,\left[7_{c}\right] C P P D$ and $\left[8_{c}\right] C P P D$ are represented using 1 and 2 . 




$\left[2_{\mathrm{t}}\right] \mathrm{CPPD}$

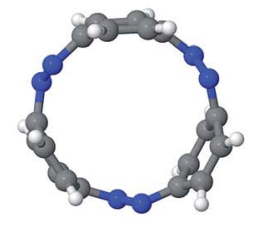

$\left[3_{t}\right] \mathrm{CPPD}$

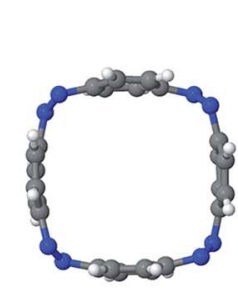

$\left[4_{t}\right]$ CPPD



$\left[5_{t}\right] \mathrm{CPPD}$

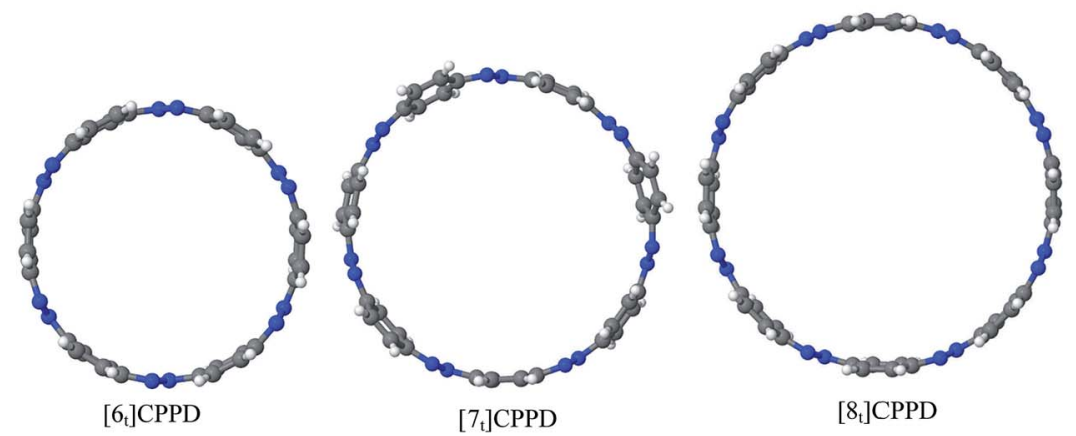

Fig. 3 Optimized structure of trans-[n]CPPDs $(n=2$ to 8) obtained using B3LYP/6-31+G(d,p) level of theory. The hydrogen, carbon, and nitrogen atoms are indicated by white, grey, and blue spheres, respectively.

combination of cis and trans isomers may be important and but is not the focused of the current study. In previous reports, researchers have shown the importance all cis and trans isomers of CPPDs. ${ }^{19,26}$ For example; Durgun and Grossman have shown the photoisomerization of all cis and all trans isomers of $\mathrm{OH}^{-}$ substituted 3-azobenzenophanes and 4-AB azobenzenophanes. ${ }^{19}$ In another study, Yuan et al. ${ }^{26}$ have predicted the host-guest interaction between only all trans-[6]CPPD and alltrans-[7]CPPD with fullerene $\left(\mathrm{C}_{60}\right)$. In the present study, we focused only on all cis and all trans form of [n]CPPDs, but in future, we plan to examine combination of cis and trans isomers of $[n]$ CPPDs.

ESI Table S5 $\uparrow$ lists some selected bond lengths and bond angles of $\left[n_{\mathrm{c}}\right] \operatorname{CPPDs}(n=2$ to 8$)$ and $\left[n_{\mathrm{t}}\right] \operatorname{CPPDs}(n=2$ to 8$)$ at the B3LYP/6-31+G(d,p). This table also includes the calculated bond lengths and bond angles of reference compounds i.e., cis and trans 1,4-bis(diazenyl)benzene (bDB), and cis and trans azobenzene $(\mathrm{AB})$ and experimentally reported value for $\mathrm{AB} . .^{50}$ The $\mathrm{C}-\mathrm{N}$ and $\mathrm{N}=\mathrm{N}$ bond distance and bond angle in $\left[2_{\mathrm{c}}\right] \mathrm{CPPD}$ and $\left[3_{c}\right] \mathrm{CPPD}$ are quantitatively similar to $\mathrm{bDB}$ and $\mathrm{AB}$. These values are in very good agreement with reported experimental values. ${ }^{50}$ The CNNC angles of $\left[2_{\mathrm{t}}\right] \mathrm{CPPD}\left(\sim 85.6^{\circ}\right),\left[3_{\mathrm{t}}\right] \mathrm{CPPD}\left(104.9^{\circ}\right)$ and $\left[4_{\mathrm{t}}\right] \mathrm{CPPD}\left(134.9^{\circ}\right)$ are smaller than strain free bDB and trans $\mathrm{AB}$ $\left(\sim 180^{\circ}\right)$. The higher deviation of angle shows maximum angle strain in the trans CPPDs series (Table S5 $\dagger$ ). As shown in the Table $55, \uparrow$ large bond distortion and dihedral angle of $\left[2_{\mathrm{t}}\right] \mathrm{CPPD}$, $\left[3_{\mathrm{t}}\right] \mathrm{CPPD}$, and $\left[4_{\mathrm{t}}\right]$ CPPD may destabilize the structures through maximizing the molecular strain energy. The $\mathrm{C}-\mathrm{N}$ and $\mathrm{N}=\mathrm{N}$ bond lengths and $\mathrm{C}-\mathrm{N}=\mathrm{N}$ bond angle of cis-[4 $\left.4_{\mathrm{c}}\right] \mathrm{CPPD}$ are different from its trans-[4 $\left.\mathrm{t}_{\mathrm{t}}\right] \mathrm{CPPD}$ isomers. This is due to the fact that cis isomer was found to be a stable boat form and trans isomer was found as a ring type structure (Fig. 2 and 3). The bond length and bond angle of higher members show a little variation compared to those cis-trans bDBs and cis-trans ABs. The dihedral angle of trans-[ $n]$ CPPDs ( $n=4$ to 8$)$ approaches $\sim 180^{\circ}$ as the number of $n$ increases, which may stabilize the structures. The calculated values of cis and trans isomers of $\mathrm{AB}$ are also in very good agreement with reported experimental a)
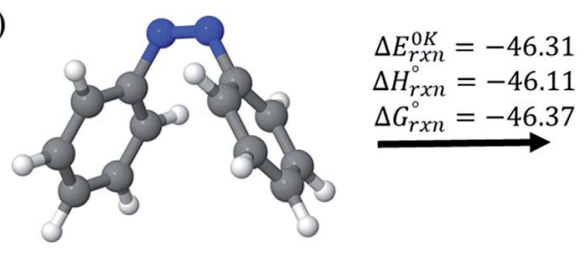

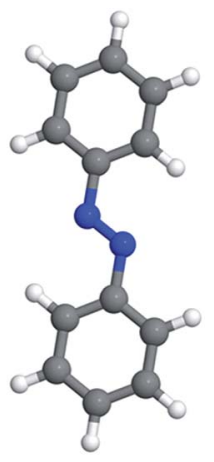

b)

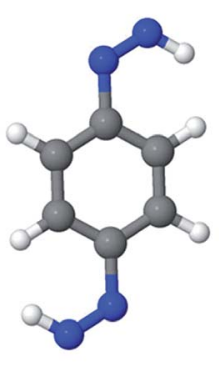

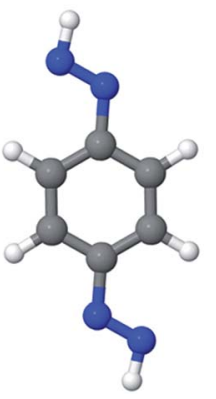

Fig. 4 Enthalpies of reaction (at $0 \mathrm{~K}$ and $298 \mathrm{~K}$ ) and Gibbs free energies (at $298 \mathrm{~K}$ ) of cis $\rightarrow$ trans isomerization of (a) azobenzene and (b) 1,4bis(diazenyl)benzene computed using G4 method. 
values. ${ }^{50}$ The point group symmetry of $[n]$ CPPDs ( $n=2$ to 8$)$ has been listed in Table S5. $\uparrow$ The point group symmetry of $\left[2_{c}\right]$ CPPD is $D_{2 \mathrm{~h}}$ which is similar to the point group symmetry of highly strained cyclic[2]paraphenyleneacetylenes ([2]CPPA) in the $[n]$ CPPAs series. However, the point group symmetry of $\left[2_{t}\right] \mathrm{CPPD}$ is $C_{2 \mathrm{~h}}$. The point group symmetry of $\left[3_{\mathrm{c}}\right] \mathrm{CPPD}\left(C_{\mathrm{s}}\right)$ and $\left[3_{\mathrm{t}}\right] \mathrm{CPPD}$ $\left(\mathrm{C}_{2}\right)$ is different from $[3] \mathrm{CPPA}\left(D_{3 \mathrm{~h}}\right)$. The generalized point group for the higher member of trans-[n]CPPDs $(n>3)$ is $D_{n}$. The point group of all $c i s$ isomers varies as $n$ increases (Table S5†). The predicted point group symmetry of cis and trans isomers of CPPDs are different from its analogous oligomer i.e., cyclicparaphenyleneacetylenes (CPPAs) and cycloparaphenylenes (CPPs). ${ }^{21-24}$

\subsection{Reaction energies}

Before considering ring systems, we first calculated $\Delta E$ (at $0 \mathrm{~K}$ ), $\Delta H$ (at $298 \mathrm{~K}$ ), and $\Delta G$ (at $298 \mathrm{~K}$ ) for the cis $\rightarrow$ trans photo isomerization of open azobenzene $(\mathrm{AB})$ and 1,4-bis(diazenyl) benzene (bDB) using G4 method (Fig. 4). The trans isomer of AB is found to be more stable than cis isomer of AB by $\sim 46.1 \mathrm{~kJ} \mathrm{~mol}^{-1}$, which is in good agreement with reported experimental value (48.5 $\mathrm{kJ} \mathrm{mol}^{-1}$ ). The G4 enthalpy $\left(46.1 \mathrm{~kJ} \mathrm{~mol}^{-1}\right)$ were also compared with theoretically calculated value $\left(55.9 \mathrm{~kJ} \mathrm{~mol}^{-1}\right)$ by Durgun and Grossmann. ${ }^{19}$ Their calculated value $\left(8-9 \mathrm{~kJ} \mathrm{~mol}^{-1}\right)$ using hybrid DFT functional is higher than that of our calculated value (46.1 $\mathrm{kJ} \mathrm{mol}^{-1}$ ) and experimentally reported one $\left(48.5 \mathrm{~kJ} \mathrm{~mol}^{-1}\right)$. In case of bDB, cis $\rightarrow$ trans photo isomerization is $\left(\sim 41 \mathrm{~kJ} \mathrm{~mol}^{-1}\right)$, this value is $\sim 5 \mathrm{~kJ} \mathrm{~mol}^{-1}$ lower than $\mathrm{AB}$.

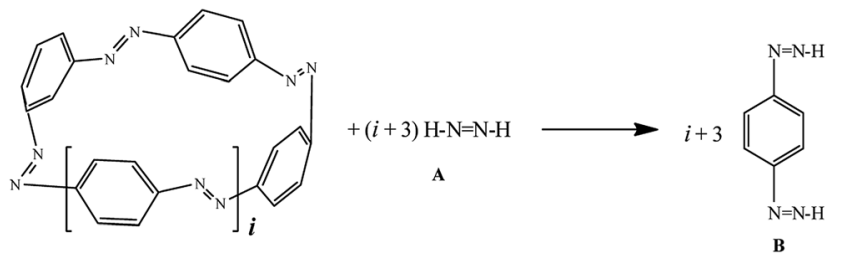

cis- $\left[\mathrm{n}_{\mathrm{c}}\right]$ CPPDs and trans-[ $\left.\mathbf{n}_{\mathrm{t}}\right]$ CPPDs

Scheme 1 Hypothetical homodesmotic reactions for the calculation of strain energies of [ $n$ ]CPPDs.

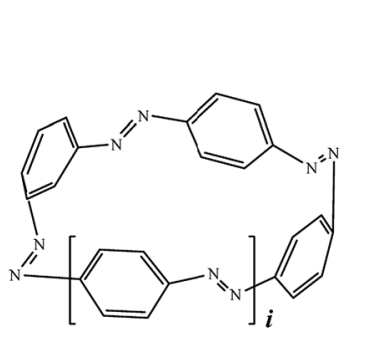

cis- $\left[\mathrm{n}_{\mathrm{c}}\right]$ CPPDs and trans- $\left[\mathrm{n}_{\mathrm{t}}\right]$ CPPDs
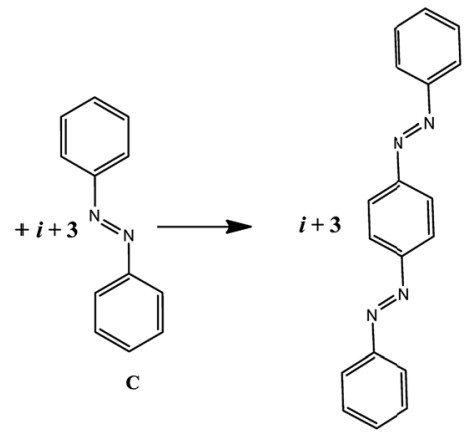

D
Scheme 2 Hypothetical homodesmotic reactions for the calculation of strain energies of $[n]$ CPPDs.
$\mathrm{AB}$ has most often served as a model system for the study of $\mathrm{N}=\mathrm{N}$ based cis and trans isomerization in CPPDs, because it absorbs light and experimentally convenient to study. Therefore, we believe that CPPDs, which contain 2 to 7 azobenzene units have been of interest in studying the steric distortion on the photochemical cis and trans isomerization. Because strainfree oligomers of CPPDs have not been reported so far, we have applied two different hypothetical homodesmotic reaction Scheme 1 (based on Ali and Krishnan study), ${ }^{21}$ and Scheme 2 (based on Segwa et al.), ${ }^{24}$ to calculate the strain energies (SE) of CPPDs. $\Delta_{\mathrm{rxn}} H_{298}^{\circ}$ calculated using both schemes are shown in Fig. 5 and tabulated in Table 1. The $\Delta_{\mathrm{rxn}} H_{298}^{\circ}$ of both schemes is lower for smaller members and increases as the number of $\mathrm{Ph}-$ $\mathrm{N}=\mathrm{N}$ linkages increase. The bar diagram (Fig. 5) shows that $\Delta_{\mathrm{rxn}} H_{298}^{\circ}$ of Scheme 1 is lower than Scheme 2, indicating HD Scheme 1 has less error compared to HD Scheme 2.

The SE at $0 \mathrm{~K}$ (i.e., with the zero-point correction included) for the all cis and all trans isomer of $[n]$ CPPDs ( $n=2$ to 8 ) were calculated using both schemes are listed in Table 1 . The difference in SE using Schemes 1 and 2 for lower members are smaller. However, for the higher member of CPPDs these values are larger. The SE of $\left[2_{\mathrm{c}}\right] \mathrm{CPPD}$ and $\left[2_{\mathrm{t}}\right] \mathrm{CPPD}$ has the highest SE in $\left[n_{\mathrm{c}}\right]$ CPPDs $(n<5)$ series, and $\left[n_{\mathrm{t}}\right]$ CPPD series, respectively. This is mostly due to its distorted $\mathrm{sp}^{2}-\mathrm{sp}^{2}-\mathrm{sp}^{2}$ angle $\left(117.2^{\circ}\right)$ in $\left[2_{\mathrm{c}}\right] \mathrm{CPPD}$ and $\left(85.6^{\circ}\right)\left[2_{\mathrm{t}}\right] \mathrm{CPPD}$. The SE of $\left[n_{\mathrm{c}}\right] \mathrm{CPPDs}(n=5$ to 8$)$ is higher than all trans-[ $\left.n_{\mathrm{t}}\right]$ CPPDs $(n=5$ to 8$)$, which may be attributed to the higher dihedral angle of cis isomer than that of trans isomer (Table S5 $\dagger$ ). The SE of all cis isomer increases linearly with adding each $\mathrm{Ph}-\mathrm{N}=\mathrm{N}$ unit. The $\mathrm{SE}$ of trans isomer decreases linearly with increasing $\mathrm{Ph}-\mathrm{N}=\mathrm{N}$ unit. The higher $\mathrm{SE}$ of $\left[8_{\mathrm{c}}\right] \mathrm{CPPD},\left[\mathrm{7}_{\mathrm{c}}\right] \mathrm{CPPD},\left[2_{\mathrm{t}}\right] \mathrm{CPPD},\left[6_{\mathrm{c}}\right] \mathrm{CPPD},\left[2_{\mathrm{c}}\right] \mathrm{CPPD},\left[3_{\mathrm{t}}\right] \mathrm{CPPD}$, $\left[4_{\mathrm{t}}\right] \mathrm{CPPD}$, and $\left[5_{\mathrm{c}}\right] \mathrm{CPPD}$ may not favour their synthesis. However, the lower SE of $\left[4_{\mathrm{c}}\right] \mathrm{CPPD},\left[3_{\mathrm{c}}\right] \mathrm{CPPD},\left[5_{\mathrm{t}}\right] \mathrm{CPPD},\left[6_{\mathrm{t}}\right]$ CPPD, $\left[7_{t}\right]$ CPPD, and $\left[8_{t}\right]$ CPPD may favour the synthesis of these molecules.



Fig. 5 Enthalpies of reaction calculated using Schemes 1 and 2. Only stable conformation of all cis of [ $n_{\mathrm{c}}$ ]CPPDs ( $n=6$ to 8 ) are shown. 
Table $1 \Delta H_{298}^{\mathrm{rxn}}\left(\mathrm{kJ} \mathrm{mol}^{-1}\right)$ and SE $\left(\mathrm{KJ} \mathrm{mol}^{-1}\right)$ calculated based on homodesmotic Schemes 1 and 2 using at B3LYP/6-31+G(d,p) level

Homodesmotic reaction schemes

\begin{tabular}{|c|c|c|c|c|c|}
\hline$\left[2_{\mathrm{c}}\right] \mathrm{CPPD}+2 \mathrm{~A} \rightarrow 2 \mathrm{~B}^{a}$ & -353.3 & 351.5 & {$\left[22_{\mathrm{t}}\right] \mathrm{CPPD}+2 \mathrm{~A} \rightarrow 2 \mathrm{~B}^{a}$} & -403.3 & 401.8 \\
\hline$\left[2_{c}\right] C P P D+2 C \rightarrow 2 D^{b}$ & -360.4 & 364.6 & {$\left[2_{t}\right] C P P D+2 C \rightarrow 2 D^{b}$} & -410.5 & 414.9 \\
\hline$\left[3_{c}\right] C P P D+3 C \rightarrow 3 D^{b}$ & -241.3 & 246.0 & {$\left[3_{t}\right] C P P D+3 C \rightarrow 3 D^{b}$} & -310.1 & 315.4 \\
\hline$\left[4_{\mathrm{c}}\right] \mathrm{CPPD}+4 \mathrm{~A} \rightarrow 4 \mathrm{~B}^{a}$ & -252.5 & 245.8 & {$\left[4_{t}\right] \mathrm{CPPD}+4 \mathrm{~A} \rightarrow 4 \mathrm{~B}^{a}$} & -340.9 & 334.7 \\
\hline$\left[4_{c}\right] C P P D+4 C \rightarrow 4 D^{b}$ & -266.8 & 272.0 & {$\left[4_{t}\right] C P P D+4 C \rightarrow 4 D^{b}$} & -355.2 & 361.0 \\
\hline${ }^{1}\left[6_{c}\right] \mathrm{CPPD}_{1}+6 \mathrm{~A} \rightarrow 6 \mathrm{~B}^{a}$ & -401.0 & 388.9 & {$\left[6_{\mathrm{t}}\right] \mathrm{CPPD}+6 \mathrm{~A} \rightarrow 6 \mathrm{~B}^{a}$} & -218.5 & 206.4 \\
\hline${ }^{2}\left[6_{c}\right] \mathrm{CPPD}_{2}+6 \mathrm{~A} \rightarrow 6 \mathrm{~B}^{a}$ & -389.0 & 377.1 & & & \\
\hline${ }^{1}\left[\sigma_{c}\right] C P P D_{1}+6 C \rightarrow 6 D^{b}$ & -422.4 & 428.2 & {$\left[\sigma_{t}\right] C P P D+6 C \rightarrow 6 D^{b}$} & -239.9 & 245.7 \\
\hline${ }^{2}\left[\sigma_{c}\right] C P P D_{2}+6 C \rightarrow 6 D^{b}$ & -410.4 & 416.5 & & & \\
\hline${ }^{1}\left[7_{\mathrm{c}}\right] \mathrm{CPPD}_{1}+7 \mathrm{~A} \rightarrow 7 \mathrm{~B}^{a}$ & -408.9 & 394.1 & {$\left[7_{\mathrm{t}}\right] \mathrm{CPPD}+7 \mathrm{~A} \rightarrow 7 \mathrm{~B}^{b}$} & -176.5 & 161.8 \\
\hline${ }^{2}\left[7_{\mathrm{c}}\right] \mathrm{CPPD}_{2}+7 \mathrm{~A} \rightarrow 7 \mathrm{~B}^{a}$ & -420.6 & 405.5 & & & \\
\hline${ }^{1}\left[8_{c}\right] C P P D_{1}+8 C \rightarrow 8 D^{a, c}$ & -517.6 & 771.4 & {$\left[8_{t}\right] C P P D+8 C \rightarrow 8 D^{a, c}$} & -182.9 & 435.8 \\
\hline${ }^{2}\left[8_{c}\right] C P P D_{2}+8 C \rightarrow 8 D^{a, c}$ & -516.5 & 771.4 & & & \\
\hline
\end{tabular}

${ }^{a} \Delta H_{298}^{\mathrm{rxn}}$ and SE calculated based on Scheme $1 .{ }^{b} \Delta H_{298}^{\mathrm{rxn}}$ and SE calculated based on Scheme $2 .{ }^{c}$ Calculated using B3LYP/6-31G(d) level. A: HN=NH; $\mathrm{B}: \mathrm{HN}=\mathrm{N}-\mathrm{Ph}-\mathrm{N}=\mathrm{NH} ; \mathrm{C}: \mathrm{Ph}-\mathrm{N}=\mathrm{N}-\mathrm{Ph} ; \mathrm{D}: \mathrm{Ph}-\mathrm{N}=\mathrm{N}-\mathrm{Ph}-\mathrm{N}=\mathrm{N}-\mathrm{Ph} ; \mathrm{Ph}$ : phenyl ring, ${ }^{1,2}$ different conformation of $c i s-\mathrm{CPPD}$.

Fig. 6 details the thermodynamic stability i.e., enthalpies and Gibbs free energies of $\left[n_{\mathrm{c}}\right]$ CPPDs and $\left[n_{\mathrm{t}}\right]$ CPPDs $(n=4$ to 8$)$ and isolated $\mathrm{AB}$ and bDB. Positive values of $\Delta H_{0 \mathrm{~K}}^{\mathrm{rxn}}$ and $\Delta G_{298 \mathrm{~K}}^{\circ}$ indicate all the cis-CPPDs is more stable, whereas negative values indicate all trans-CPPDs are more stable. In all cases $(n=$ 5 to 8), trans isomers are more stable than cis isomers, however, for $n=4$, cis isomer is more stable than the trans isomer. This is due to the fact that $\left[4_{\mathrm{c}}\right] \mathrm{CPPD}$ is less strained compared to $\left[4_{\mathrm{t}}\right]$ CPPD (see Fig. 2 and Table S5 $\dagger$ ). The computed ZPE, thermal correction $\left(H_{\mathrm{T}}\right)$, and entropy of all cis and all trans isomers are in tabulated in the ESI (Table S6 $\dagger$ ). The $\Delta \mathrm{ZPE}, \Delta H_{\mathrm{T}}$, and $\Delta S$ of cis

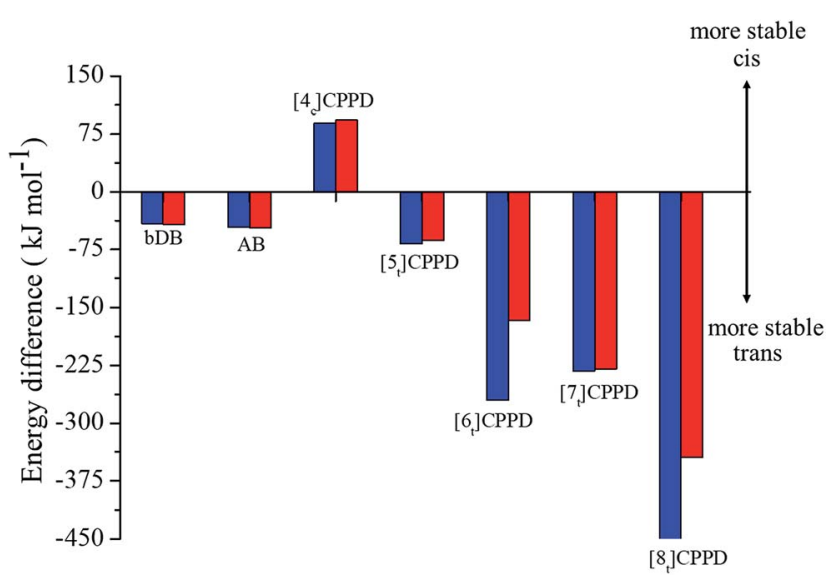

Fig. 6 Enthalpy difference $\left(\Delta H_{0}^{\mathrm{rxn}} \mathrm{K}\right)$ and Gibbs free energy $\left(\Delta G_{298}^{\circ} \mathrm{K}\right)$ change between cis and trans isomers. Blue line corresponds to $\Delta H_{0}^{r \times n}$ and red line corresponds to $\Delta G_{298}^{\circ}$ K. $\rightarrow$ trans transformation isomers are very small. The relatively smaller value of $\Delta \mathrm{S}$ can be explained by assuming that the isomerization of cis-CPPDs or trans-CPPDs can start from a structure that has the smaller degree of freedom because of the strain caused by a cyclic structure.

The calculated SE of $[n]$ CPPDs $(n=4$ to 8$)$ are compared with previously calculated SE of $[n]$ CPPs and $[n]$ CPPAs $(n=4$ to 8$)$ as shown in Fig. 7. The SE of $\left[n_{\mathrm{t}}\right]$ CPPDs decreases with increasing $\mathrm{Ph}-\mathrm{N}=\mathrm{N}$ units, which is consistent with $[n]$ CPPAs (strain energies decreases linearly as $\mathrm{Ph}-\mathrm{C} \equiv \mathrm{C}$ ) and CPPs (SE decreases

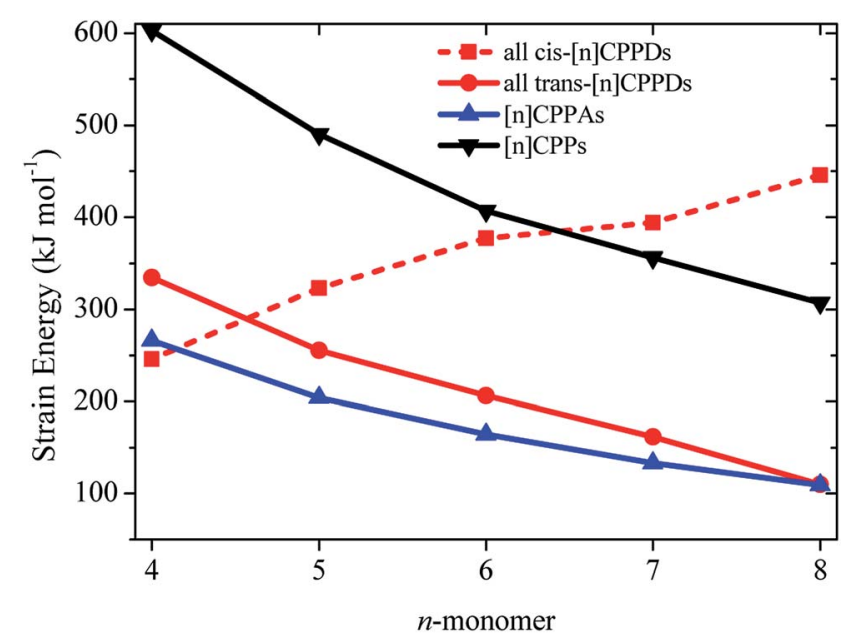

Fig. 7 Comparison of SE calculated using homodesmotic Scheme 1 for $[n]$ CPPDs $(n=4$ to 8$)$ and the SE value of [ $n$ ]CPPAs $(n=4 \text { to } 8)^{21}$ and [n]CPPs $(n=4$ to 8$) .{ }^{23,24}$ 
(a)

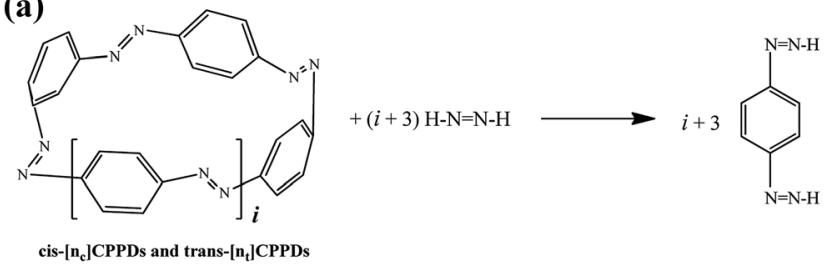

(b)

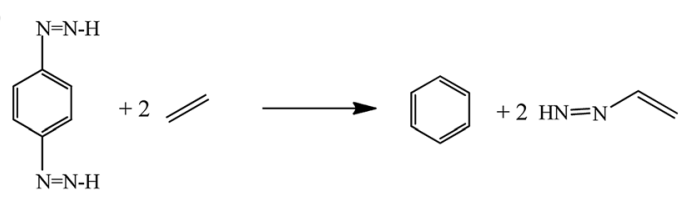

Scheme 3 Hypothetical homodesmotic reactions for the calculation of $\Delta_{\mathrm{f}} H_{298}^{\circ}$ of all cis and all trans-[n]CPPDs.

linearly as $\mathrm{Ph}$ - unit increases). The SE of $\left[4_{\mathrm{c}}\right] \mathrm{CPPD},\left[5_{\mathrm{c}}\right] \mathrm{CPPD}$, and $\left[6_{c}\right] \mathrm{CPPD}$ are lower than that of $[4] \mathrm{CPP}$, [5]CPP, and [6]CPP respectively. The SE value for $\left[7_{c}\right] \mathrm{CPPD}$ and $\left[8_{\mathrm{c}}\right] \mathrm{CPPD}$ are higher than that of respective [7]CPP and [8]CPP. This effect is due to the twisted structure, which imposes higher dihedral angle in the higher member of CPPDs. If we compare the SE of trans isomer of CPPDs with CPPAs and CPPs, the order of SE of these oligomer are $[n]$ CPPs $>\left[n_{\mathrm{t}}\right]$ CPPDs $>[n]$ CPPAs $(n=4$ to 7$)$.

$\mathrm{SE}$ is a good indicator in the feasibility of synthesis process. Some of the carbon nanoring structure i.e., [5]CPP (490.5 kJ mol$\left.{ }^{-1}\right)$, [6]CPP (406.8 $\left.\mathrm{kJ} \mathrm{mol}^{-1}\right)$, [7]CPP $\left(356.5 \quad \mathrm{~kJ}^{-1} \mathrm{~mol}^{-1}\right), \quad[8] \mathrm{CPP} \quad\left(307.1 \quad \mathrm{~kJ}^{-1} \mathrm{~mol}^{-1}\right), \quad[9] \mathrm{CPP}$ $\left(274.5 \quad \mathrm{~kJ} \quad \mathrm{~mol}^{-1}\right), \quad[12] \mathrm{CPP} \quad\left(201.3 \quad \mathrm{~kJ}^{-1} \mathrm{~mol}^{-1}\right), \quad[18] \mathrm{CPP}$ (132.6 $\left.\mathrm{kJ} \mathrm{mol}^{-1}\right)$, [6]CPPA $\left(164.4 \quad \mathrm{~kJ}^{-1} \mathrm{~mol}^{-1}\right)$, [7]CPPA $\left(133.3 \mathrm{~kJ} \mathrm{~mol}^{-1}\right)$, and [8]CPPA $\left(109.4 \mathrm{~kJ} \mathrm{~mol}^{-1}\right)$ have already been synthesized by various research groups..$^{22,23,51-53}$ Therefore, we believe the same synthetic strategies may also be

Table $2 \quad \Delta_{\mathrm{f}} H_{298}^{\circ}\left(\mathrm{kJ} \mathrm{mol}^{-1}\right), \Delta_{\mathrm{f}} H_{298}^{\circ} / n-\mathrm{SE} / n\left(\mathrm{~kJ} \mathrm{~mol}^{-1}\right)$ and enthalpies of combustion $\left(\mathrm{kJ} \mathrm{mol}^{-1}\right)$ for [ $n$ ]CPPDs ( $n=2$ to 8 )

\begin{tabular}{lllll}
\hline$[n]$ CPPDs & $\Delta_{\mathrm{f}} H_{298}^{\circ}$ & $\Delta_{\mathrm{f}} H_{298}^{\circ} / n-\mathrm{SE} / n$ & $\Delta_{\text {comb }} H_{298}^{\circ}{ }^{a}$ & $\Delta_{\text {comb }} H_{298}^{\circ}{ }^{b}$ \\
\hline$\left[2_{\mathrm{c}}\right] \mathrm{CPPD}$ & 1009 & 328.8 & -6698.1 & $-32.2^{b}$ \\
{$\left[2_{\mathrm{t}}\right] \mathrm{CPPD}$} & 1059.1 & 328.7 & -7722.6 & -37.1 \\
{$\left[3_{\mathrm{c}}\right] \mathrm{CPPD}$} & 1214.3 & 329.6 & -9747.9 & -31.2 \\
{$\left[3_{\mathrm{t}}\right] \mathrm{CPPD}$} & 1283.1 & 320.1 & -10794.6 & -34.6 \\
{$\left[4_{\mathrm{c}}\right] \mathrm{CPPD}$} & 1564.1 & 329.6 & -12942.2 & -31.1 \\
{$\left[4_{\mathrm{t}}\right] \mathrm{CPPD}$} & 1652.5 & 329.4 & -13044.8 & -31.3 \\
{$\left[5_{\mathrm{c}}\right] \mathrm{CPPD}$} & 1972.2 & 329.8 & -16194.7 & -31.1 \\
{$\left[5_{\mathrm{t}}\right] \mathrm{CPPD}$} & 1904.0 & 329.7 & -16144.3 & -31.0 \\
{$\left[6_{\mathrm{c}}\right] \mathrm{CPPD}$} & 2368.4 & 329.9 & -19435.5 & -31.1 \\
{$\left[6_{\mathrm{c}}\right] \mathrm{CPPD}_{2}$} & 2356.4 & 329.9 & -19423.4 & -31.1 \\
{$\left[6_{\mathrm{t}}\right] \mathrm{CPPD}$} & 2185.9 & 329.9 & -19274.3 & -30.8 \\
{$\left[7_{\mathrm{c}}\right] \mathrm{CPPD}_{1}$} & 2704.2 & 330.0 & -22615.7 & -31.1 \\
{$\left[7_{\mathrm{c}}\right] \mathrm{CPPD}_{2}$} & 2715.9 & 330.1 & -22627.4 & -31.1 \\
{$\left[7_{\mathrm{t}}\right] \mathrm{CPPD}^{2}$} & 2471.8 & 330.0 & -22408.3 & -30.7 \\
{$\left[8_{\mathrm{c}}\right] \mathrm{CPPD}_{1}$} & 3086.3 & 330.1 & -25842.4 & -31.0 \\
{$\left[8_{\mathrm{c}}\right] \mathrm{CPPD}_{2}$} & 3085.2 & 330.0 & -25841.3 & -31.0 \\
{$\left[8_{\mathrm{t}}\right] \mathrm{CPPD}^{2}$} & 2751.6 & 330.2 & -25562.1 & -30.6
\end{tabular}

${ }^{a}$ A generalised combustion reaction of $[n]$ CPPDs: $[n]$ CPPDs $+7 n \mathrm{O}_{2} \rightarrow$ $6 n \mathrm{CO}_{2}+2 n \mathrm{H}_{2} \mathrm{O}+n \mathrm{~N}_{2} .{ }^{b}$ Molar enthalpy of combustion (in kJ g ${ }^{-1}$ ). applied for the synthesis of all cis and all trans isomers of CPPDs with lower SE values.

The standard enthalpies of formation $\left(\Delta_{\mathrm{f}} H_{298}^{\circ}\right)$ is a fundamental quantity in the estimation of the energy stored in $[n]$ CPPDs ( $n=2$ to 8). $\Delta_{\mathrm{f}} H_{298}^{\circ}$ is calculated using the combination of homodesmotic reactions (Schemes 3a and b). The $\Delta_{\mathrm{f}} H_{298}^{\circ}$ of cis and trans isomers of CPPDs are shown in Table 2. The experimental $\Delta_{\mathrm{f}} H_{298}^{\circ}$ of 1,4 -bis(diazenyl)benzene (bDB) is unknown. Therefore, our calculation of $\Delta_{\mathrm{f}} H_{298}^{\circ}$ of bDB is based on another homodesmotic approach (Scheme $3 \mathrm{~b}$ ). The $\Delta_{\mathrm{f}} H_{298}^{\circ}$ of bDB is calculated using high-level quantum composite Gaussian-4 method. ${ }^{49}$ The experimental gas-phase $\Delta_{\mathrm{f}} H_{298}^{\circ} \mathrm{K}$ of benzene $\left(82.8 \mathrm{~kJ} \mathrm{~mol}^{-1}\right)^{54}$ and ethylene $\left(20.4 \mathrm{~kJ} \mathrm{~mol}^{-1}\right)$ is used to obtain the value of bDB $\left(522.9 \mathrm{~kJ} \mathrm{~mol}^{-1}\right)$. However, the experimental $\Delta_{\mathrm{f}} H_{298}^{\circ} \mathrm{K}$ of reference $\mathrm{HN}=\mathrm{NCH}=\mathrm{CH}_{2}$ is not known. Therefore, our calculation of $\Delta_{\mathrm{f}} H_{298}^{\circ}$ for $\mathrm{HN}=\mathrm{NCH}=\mathrm{CH}_{2}$ is based on another hypothetical isodesmic reaction $(\mathrm{HN}=$ $\left.\mathrm{NCH}=\mathrm{CH}_{2}+\mathrm{CH}_{4} \rightarrow \mathrm{H}_{3} \mathrm{CN}=\mathrm{NH}+\mathrm{C}_{2} \mathrm{H}_{4}\right)$. The experimental $\Delta_{\mathrm{f}} H_{298}^{\circ}$ for $\mathrm{CH}_{3} \mathrm{~N}=\mathrm{NH}$ is taken from Matus et al. study ${ }^{55}$ for the calculation of $\Delta_{\mathrm{f}} \mathrm{H}_{298}^{\circ}$ for $\mathrm{HN}=\mathrm{NCH}=\mathrm{CH}_{2}$. The calculated $\Delta_{\mathrm{f}} \mathrm{H}_{298}^{\circ}$ of $\mathrm{HNNCH}=\mathrm{CH}_{2}$ using isodesmic reaction approach is $266.8 \mathrm{~kJ} \mathrm{~mol}^{-1}$. The $\Delta_{\mathrm{f}} H_{298}^{\circ}$ per-unit monomer of all cis and all trans isomers of $[n]$ CPPDs ( $n=2$ to 8$)$ are shown in Fig. 8 . The $\Delta_{\mathrm{f}} H_{298}^{\circ}$ per-unit monomer of all cis isomer is higher than that of all trans isomers indicating the higher strain and less stable compared to trans isomers. The $\Delta_{\mathrm{f}} \mathrm{H}_{298}^{\circ}$ per-unit monomer of $c i s$ isomer reaches to the plateau for $n=7$ and 8. However, for the trans isomer $\Delta_{\mathrm{f}} H_{298}^{\circ}$ per-unit monomer decreases linearly. We have also calculated energy difference between $\Delta_{\mathrm{f}} H_{298}^{\circ} / n-\mathrm{SE} / n$ for $[n]$ CPPDs (Table 2). The average $\Delta_{\mathrm{f}} H_{298}^{\circ} / n-\mathrm{SE} / n$ value for all cis and all trans-[n]CPPDs is $\sim 330 \mathrm{~kJ} \mathrm{~mol}^{-1}$. This value is very close to $\Delta_{\mathrm{f}} H_{298}^{\circ}$ of strain free $\mathrm{Ph}-\mathrm{N}=\mathrm{N}-\mathrm{H}\left(334 \mathrm{~kJ} \mathrm{~mol}^{-1}\right)$.

Table 2 also contains the enthalpies of combustion $\left(\Delta_{\text {comb }} H_{298}^{\circ}\right)$ and molar enthalpy of combustion. It can be seen that absolute value for CPPDs is $\sim-(30-32) \mathrm{kJ} \mathrm{g}^{-1}$ indicating the release a large amount of energy during the combustion of CPPDs. Moreover, the replacement of $\mathrm{N}=\mathrm{N}$ bond by $\mathrm{C} \equiv \mathrm{C}$ bond

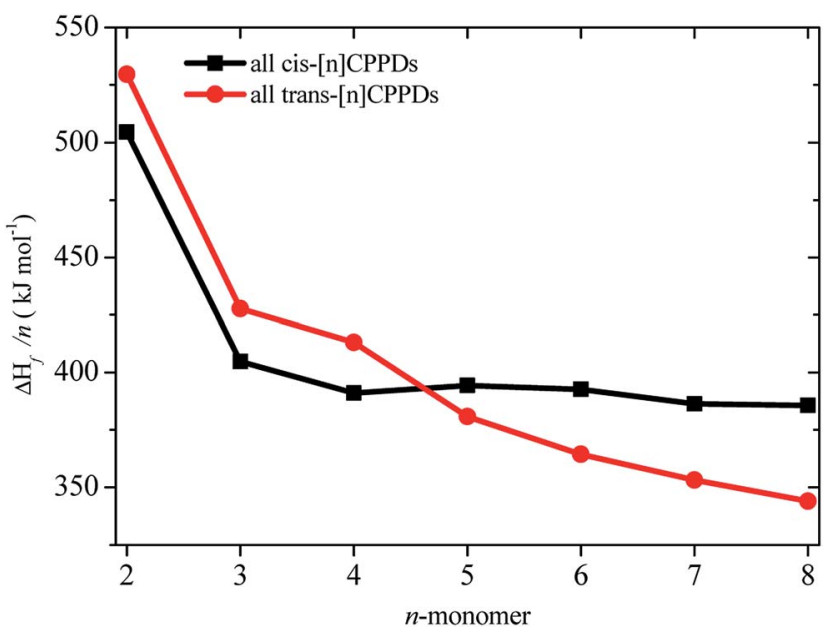

Fig. $8 \Delta_{\mathrm{f}} H_{298}^{\circ}$ per-unit monomer of all cis and all trans isomers of [ $n$ ] CPPDs ( $n=2$ to 8 ). 


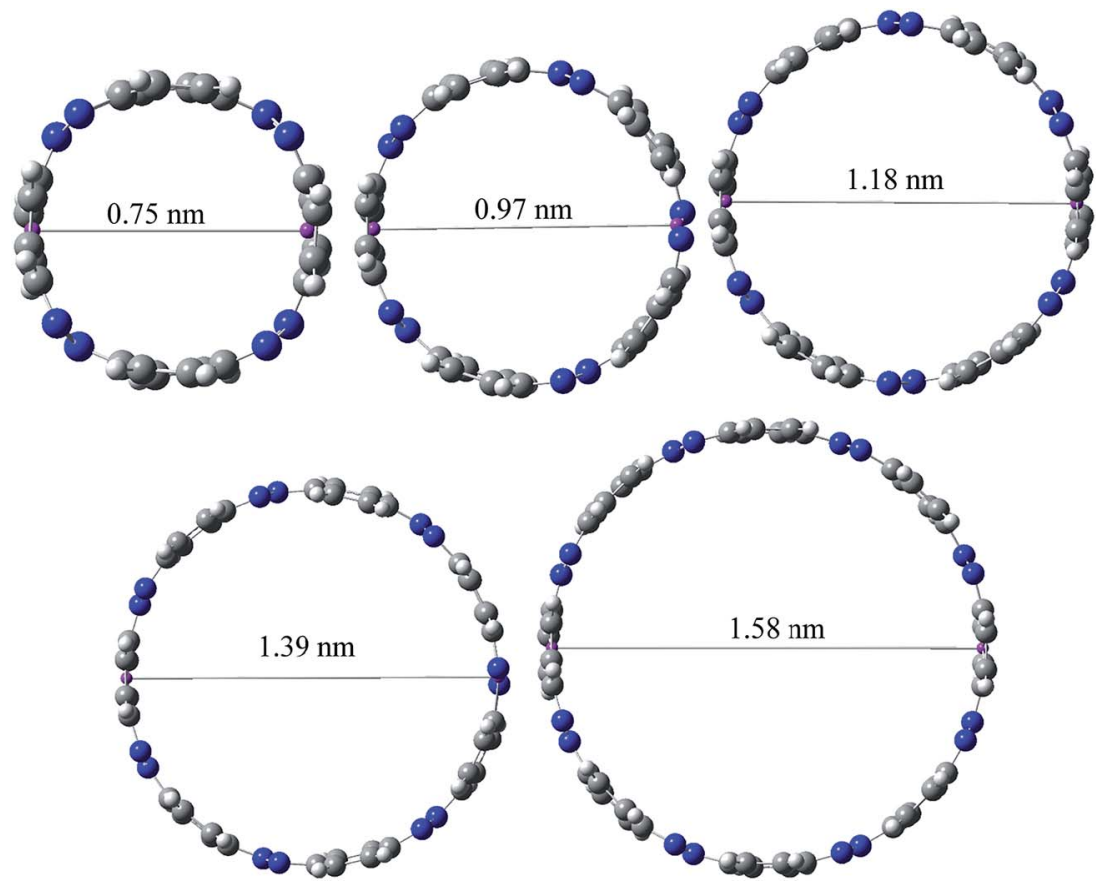

Fig. 9 Ring diameters for trans- $\left[n_{\mathrm{t}}\right]$ CPPDs ( $n=4$ to 8 ).

in CPPDs results in increasing the $\mathrm{C}$ atoms, leading to a relatively higher absolute value of $\Delta_{\text {comb }} H_{298}^{\circ}$ for CPPAs. This indicates that $\mathrm{C}$ atoms contribute $\sim 8-9 \mathrm{~kJ} \mathrm{~g}^{-1}$ energy through the formation of carbon dioxide during combustion, which can explain the higher $\Delta_{\mathrm{comb}} \mathrm{H}_{298}^{\circ}$ of CPPAs than that of CPPDs.

\subsection{Electronic properties of $[\boldsymbol{n}] \mathrm{CPPDs}$}

Ring diameter is good indicator of host-guest chemistry ${ }^{26}$ of $[n]$ CPPDs and it is estimated as the distance between the centres of mass of the opposite benzene ring for the even member of all trans CPPDs i.e., $\left[4_{\mathrm{t}}\right] \mathrm{CPPD},\left[6_{\mathrm{t}}\right] \mathrm{CPPD}$, and $\left[8_{\mathrm{t}}\right] \mathrm{CPPD}$ and the distance between the nitrogen atom and the center of mass of the opposite benzene ring for the odd number of trans CPPDs i.e., $\left[5_{t}\right]$ CPPD and $\left[7_{t}\right]$ CPPD (see Fig. 9). As expected, when azo groups are all in trans configuration, the nanorings are in open state in which the cavities are available and when the azo groups are all in cis forms, they are in the closed state in which the cavities are deformed or collapsed. The cavity diameter $\left(D_{n}\right)$ from $\left[4_{\mathrm{t}}\right] \mathrm{CPPD}$ to $\left[8_{\mathrm{t}}\right] \mathrm{CPPD}$ evolves linearly with increasing phenylenediazene units $(n)$; for example, the $\mathrm{B} 3 \mathrm{LY} / 6-31+\mathrm{G}(\mathrm{d}, \mathrm{p})$ results can be described by equation (the regression coefficient is 0.99968 )

$$
D_{n}(\mathrm{~nm})=-0.074+n \times 0.208 .
$$

The trend of ring diameters is similar to SE of $\left[n_{\mathrm{t}}\right]$ CPPDs $(n=$ 4 to 8 ). When the size of the system increases, SE decreasing with increasing the ring diameter. The calculated ring diameter of $\left[6_{t}\right]$ CPPDs $(1.18 \mathrm{~nm})$ and $\left[7_{t}\right]$ CPPDs $(1.39 \mathrm{~nm})$ are also in very good agreement with the values reported by Yuan et al. ${ }^{26}$ for $[6 \mathrm{t}]$ CPPD $(1.19 \mathrm{~nm})$ and [ $\left.7_{\mathrm{t}}\right] \mathrm{CPPD}(\sim 1.39 \mathrm{~nm})$ calculated using M06$2 \mathrm{X} / 6-31 \mathrm{G}(\mathrm{d})$ level of theory. Moreover, comparing the diameter of $\left[n_{\mathrm{t}}\right]$ CPPDs $(n=4$ to 8$)$ with their analogous $[n]$ CPPAs $(n=4$ to $8)$ and $[n]$ CPPs $(n=4$ to 8$)$ nanorings (ESI Table S7 $\dagger$ ). The values of $\left[n_{\mathrm{t}}\right]$ CPPDs ( $n=4$ to 8 ) are lower than those of corresponding $[n]$ CPPAs and $[n]$ CPPs.
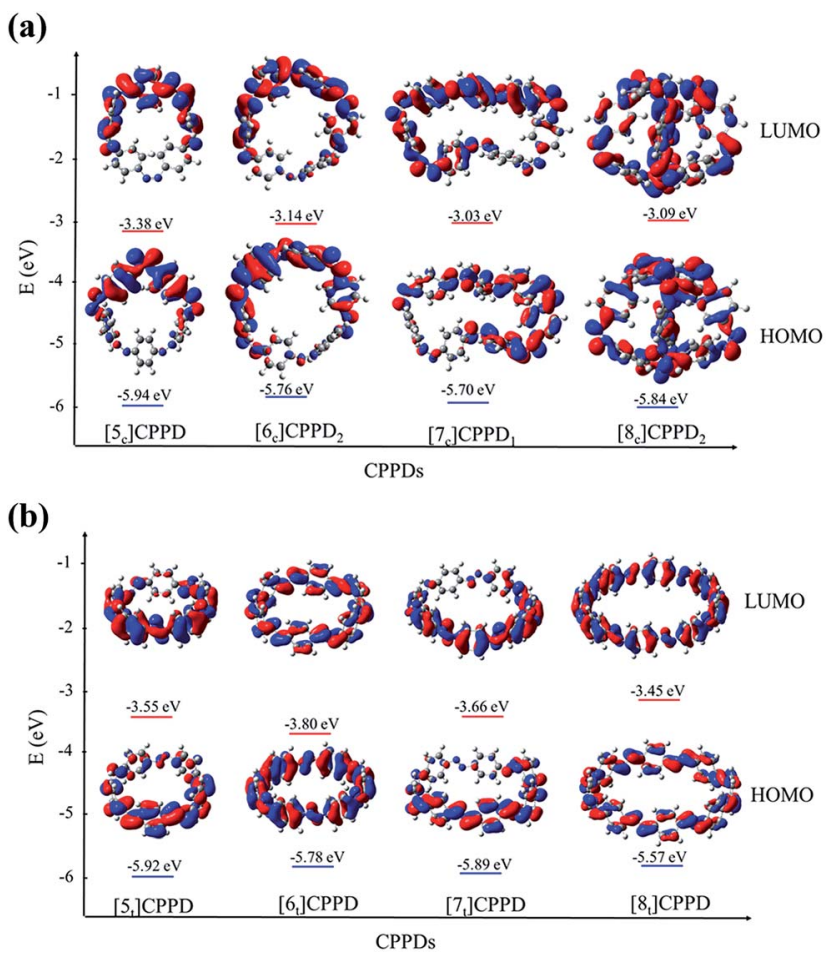

Fig. 10 (a) Spatial distribution (0.02 au) and energy level diagram of HOMO and LUMO orbitals for cis isomer of [n]CPPD ( $n=5$ to 8 ). (b) Spatial distribution (0.02 au) and energy level diagram of $\mathrm{HOMO}$ and LUMO orbitals for trans isomers of [n]CPPDs ( $n=5$ to 8 ). 
The cavity size of $\left[6_{\mathrm{t}}\right] \mathrm{CPPD}(1.18 \mathrm{~nm})$ is almost comparable to that of $(1.01 \mathrm{~nm})$ carbon nanotube, and it appears to be suitable for the inclusion of $\mathrm{C}_{60}(0.7 \mathrm{~nm}$ in diameter $)$. In the previous study, Zhao and Truhlar $^{56}$ have calculated the interaction energies of guest molecules such as three arm-chair-type nanotubes; $(3,3),(4,4)$, and $(5,5)$ with the host molecules such as [6]CPPA, $(3,3)[6] \mathrm{CPPA},(4,4)[6] \mathrm{CPPA}$, and $(5,5)[6] \mathrm{CPPA}$ using the density functional theory. In another study, Bachrach and Zayat $^{57}$ have calculated binding free energies of host [14] CPP and guest molecule $[n] \mathrm{CPP}(n=6$ to 10$)$, [14]CPP [6]CPP, [14]CPP [7]CPP, [14]CPP [7]CPP, [14]CPP [8]CPP, [14]CPP [9]CPP, and [14]CPP [10]CPP using $\omega$ B97X-D/6-31G(d) level calculation. In 2015, Yuan et al. ${ }^{26}$ have predicted the host-guest interaction between [6]CPPD nanoring with $\mathrm{C}_{60}$. Recently, Lee et al. ${ }^{58}$ have synthesized [3]CPP $\mathrm{C}_{70}$ and [3]CPPA $\mathrm{C}_{70}$ and calculated cavity diameter using B3LYP/6-31G(d) level of theory. A similar

Table 3 Comparison of structural properties and SE of CPPDs with carbon nanoring models

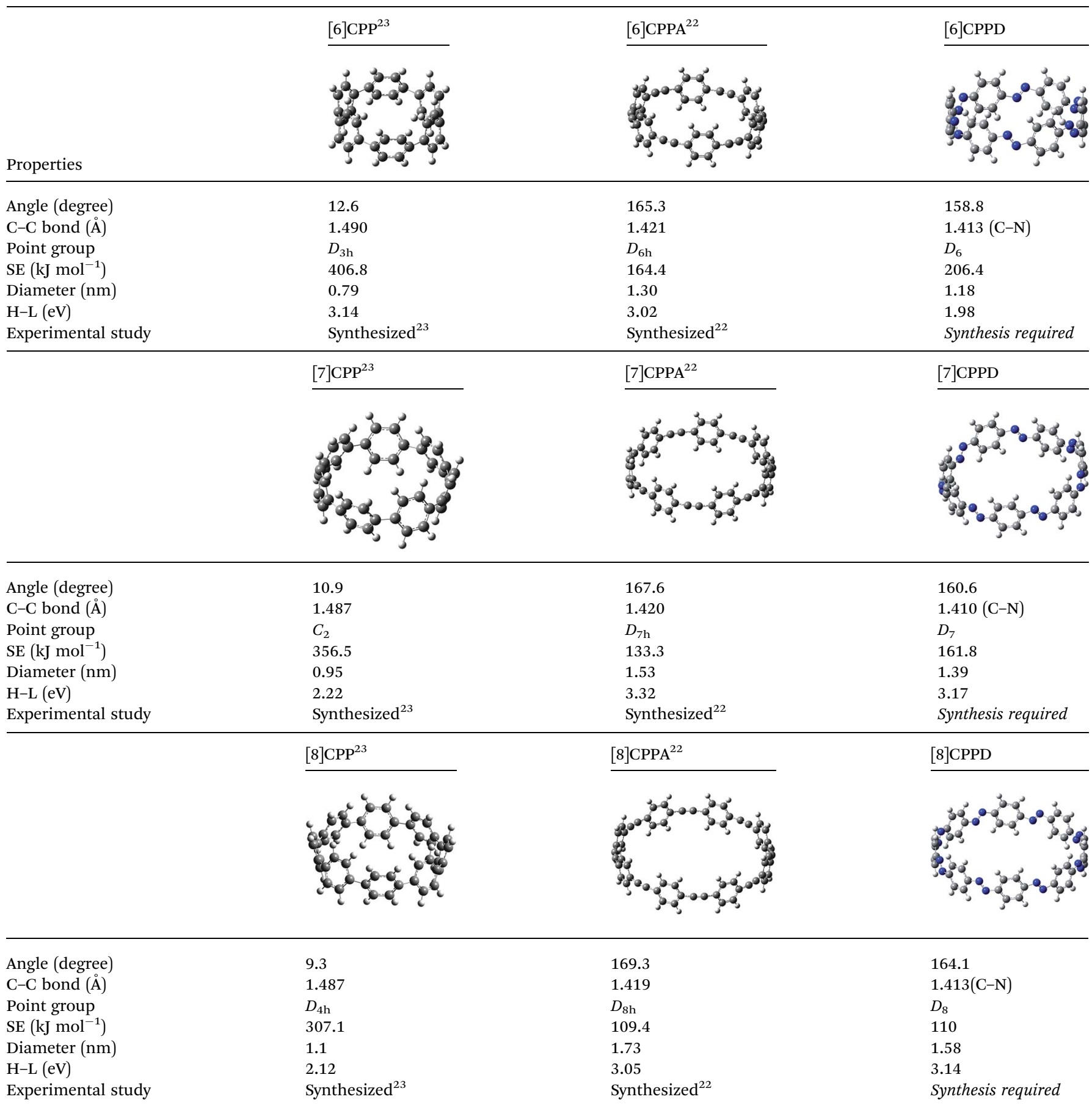


approach can be applied to design host-guest systems with host CPPDs and guest molecules such as $\mathrm{C}_{60}, \mathrm{C}_{70},(3,3),(4,4)$ and $(5,5)$, CPPs, and CPPAs to understand the chemical and electronic properties.

Molecular orbital is an important parameter, which can provide useful information on the electronic structure and a decisive factor indicating potential material for the construction of solar cells. The calculated highest occupied molecular orbitals (HOMO) and lowest unoccupied molecular orbitals (LUMO) are provided in ESI Table S7 $\dagger$ and their spatial distribution are shown in Fig. 10. The HOMO and LUMO of [6 6 $\mathrm{CPPD}_{1},\left[6_{\mathrm{t}}\right] \mathrm{CPPD}$, and $\left[8_{\mathrm{t}}\right] \mathrm{CPPD}$ show the uniform orbital density located at all atoms in the skeleton, whereas the HOMO and LUMO of $\left[5_{c}\right] \mathrm{CPPD},\left[6_{\mathrm{c}}\right] \mathrm{CPPD}_{2},\left[5_{\mathrm{t}}\right] \mathrm{CPPD}$, and $\left[7_{\mathrm{c}}\right] \mathrm{CPPD}_{1},\left[7_{\mathrm{t}}\right]$ CPPD have non-uniform orbital density on $\mathrm{Ph}-\mathrm{N}=\mathrm{N}$ unit. The HOMO and LUMO levels of $\left[5_{t}\right]$ CPPD and $\left[7_{t}\right]$ CPPD are 2 -fold degenerate, which indicate that the removal of an electron from the HOMO level or addition of an electron to the LUMO level could weaken the skeleton framework. ${ }^{59}$ The values of HOMOs and LUMOs of the odd trans-CPPDs are higher than that of even trans-CPPDs. However, the odd-even trend was not observed in cis-CPPDs. This is probably due to conformational differences of the odd and even CPPDs as described above. The spatial distribution of HOMO-LUMO gap for CPPDs were also compared with CPPs and CPPAs. As for CPPDs, the HOMO and LUMO distribution are quite different from CPPAs and CPPs.

Table $\mathrm{S} 7 \dagger$ also includes the HOMO-LUMO gap values for CPPAs and CPPs. The HOMO-LUMO gap of CPPDs is in between 1.98 and $2.85 \mathrm{eV}$, for CPPAs (2.99 to $3.05 \mathrm{eV}$ ) and for CPPs (2.55-3.41 eV). The predicted HOMO-LUMO gap of all cisCPPDs and all trans CPPDs have smaller values than that of CPPAs and CPPs. Our calculations also suggest that adding nitrogen atoms in CPPs decreases the HOMO-LUMO gap, which is in consistent with the data reported by Van Raden et al. ${ }^{27}$ who have also predicted the decreasing value of HOMOLUMO gap of nitrogen doped CPP i.e., azo[6]CPP. The predicted HOMO-LUMO gap of CPPDs are in the range of the material used in the construction of solar cells. The results suggest that CPPDs oligomer are better candidate for building solar cells than CPPAs and CPPs.

\subsection{Comparison of CPPDs with carbon nanorings (CNRs)}

The structure, electronic properties, and thermochemistry of all trans- $[n]$ CPPDs ( $n=6$ to 8 ) were compared with its analogous carbon nanoring structure i.e., $[n]$ CPPs and $[n]$ CPPAs $(n=6$ to 8$)$ are given in Table 3 . Results indicate that nitrogen substituted cyclic para phenyl oligomer have higher strain energies compared to acetylene substituted cyclic paraphenyl oligomer. However, strain energies of CPPs are higher than the strain energies of CPPAs and CPPDs. The ring diameter of all three species are also correlated with molecular strain. The lower value of diameter of nanoring has higher strain energies and higher value of diameter has lower strain energies. The HOMOLUMO gap of these nanorings suggests that CPPDs could be the good material for the construction of solar cells. In addition, it may be possible to design host-guest systems with hosts; [6]
CPPD, [7]CPPD, and [8]CPPD with guest molecules; $\mathrm{C}_{60}, \mathrm{C}_{70}$, CPPs $(3,3),(4,4)$ and $(5,5)$, CPPAs and carbon nanotubes to understand their chemistry. The predicted structure, SE, and electronic properties of CPPDs with carbon nanoring structure (CPAs and CPPAs) (Table 3 ), suggest that $\left[6_{t}\right]$ CPPD, $\left[7_{t}\right]$ CPPD, and $\left[8_{t}\right]$ CPPD can be synthesized in the laboratory.

\section{Conclusions}

We have provided the theoretical calculation related to the structure, strain energies (SE), standard enthalpies of formation $\left(\Delta_{\mathrm{f}} H_{298}^{\circ}\right)$, and electronic properties of the novel structures of all cis and all trans isomers of $[n]$ CPPDs $(n=2$ to 8$)$. The calculations of SE and $\Delta_{\mathrm{f}} H_{298}^{\circ}$ are based on homodesmotic reaction approach and B3LYP hybrid DFT method with 6-31+G(d,p) basis set. The SE and ring diameter of CPPDs indicate $\left[6_{t}\right]$ CPPD, $\left[7_{t}\right]$ CPPD, and $\left[8_{t}\right]$ CPPD are the ideal molecules for the future experimental study. The unique behaviour of HOMO and LUMO of CPPDs compared to CPPAs and CPPs opens a new possibility of CPPDs for applications in optoelectronics. The trends observed for ring systems presented here are not just limited to CPPDs but rather applicable to a wide range of photo convertible molecules. Our campaign toward the design of mix combination of CPPDs is underway and will be reported in future. We believe that the ring effect uncovered in this study may find uses in the emerging field of organic electronics. The present study should help us not only to plan a new synthetic strategy but also to understand the structural, electronic, physical properties, and the host-guest chemistry of other nitrogen doped cyclic oligomer.

\section{Conflicts of interest}

There are no conflicts to declare.

\section{Acknowledgements}

Author gratefully acknowledge the computational resources at KISTI super computer facility in the South Korea. MAA thanks Sejong University Seoul for the research support. MAA thanks Professor John R. Barker from University of Michigan for useful suggestions. We thank the anonymous reviewers for helpful suggestions, including the suggestion to find out other conformations of cis and trans-CPPDs. M. A. Alam thanks, ABIA-State (Grant number: Start-up 200127) for supporting.

\section{References}

1 C. Pu, D. Zhou, Y. Li, H. Liu, Z. Chen, Y. Wang and Y. Ma, J. Phys. Chem. C, 2017, 121, 2669-2674.

2 Y. Liu, A. Singharoy, C. G. Mayne, A. Sengupta, K. Raghavachari, K. Schulten and A. H. Flood, J. Am. Chem. Soc., 2016, 138, 4843-4851.

3 X. Wang, X. Li, L. Zhang, Y. Yoon, P. K. Weber, H. Wang, J. Guo and H. Dai, Science, 2009, 324, 768-771.

4 T. Cui, R. Lv, Z.-H. Huang, H. Zhu, J. Zhang, Z. Li, Y. Jia, F. Kang, K. Wang and D. Wu, Carbon, 2011, 49, 5022-5028. 
5 L. Qu, Y. Liu, J. B. Baek and L. Dai, ACS Nano, 2010, 4, 13211326.

6 A. L. M. Reddy, A. Srivastava, S. R. Gowda, H. Gullapalli, M. Dubey and P. M. Ajayan, ACS Nano, 2010, 4, 6337-6342.

7 W. R. Browne and B. L. Feringa, Nat. Nanotechnol., 2006, 1, 25-35.

8 T. Hugel, N. B. Holland, A. Cattani, L. Moroder, M. Seitz and H. E. Gaub, Science, 2002, 296, 1103-1106.

9 H. M. Jeong, J. W. Lee, W. H. Shin, Y. J. Choi, H. J. Shin, J. K. Kang and J. W. Choi, Nano Lett., 2011, 11, 2472-2477.

10 A. Khan, C. Kaiser and S. Hecht, Angew. Chem., Int. Ed., 2006, 45, 1878-1881.

11 K. K. Cotí, M. E. Belowich, M. Liong, M. W. Ambrogio, Y. A. Lau, H. A. Khatib, J. I. Zink, N. M. Khashab and J. F. Stoddart, Nanoscale, 2009, 1, 16-39.

12 Y. Yang, R. P. Hughes and I. Aprahamian, J. Am. Chem. Soc., 2014, 136, 13190-13193.

13 W. A. Velema, W. Szymanski and B. L. Feringa, J. Am. Chem. Soc., 2014, 136, 2178-2191.

14 D. Hoersch, S.-H. Roh, W. Chiu and T. Kortemme, Nat. Nanotechnol., 2013, 8, 928-932.

15 J. E. Koskela, V. Liljeström, J. Lim, E. E. Simanek and R. H. Ras, J. Am. Chem. Soc., 2014, 136, 6850-6853.

16 Y. Norikane, K. Kitamoto and N. Tamaoki, J. Org. Chem., 2003, 68, 8291-8304.

17 S. A. Nagamani, Y. Norikane and N. Tamaoki, J. Org. Chem., 2005, 70, 9304-9313.

18 H. Rau and E. Lueddecke, J. Am. Chem. Soc., 1982, 104, 16161620.

19 E. Durgun and J. C. Grossman, J. Phys. Chem. Lett., 2013, 4, 854-860.

20 J. Olmsted III, J. Lawrence and G. G. Yee, Sol. Energy, 1983, 30, 271-274.

21 M. A. Ali and M. S. Krishnan, Mol. Phys., 2009, 107, 21492158.

22 T. Kawase and H. Kurata, Chem. Rev., 2006, 106, 5250-5273.

23 E. R. Darzi and R. Jasti, Chem. Soc. Rev., 2015, 44, 6401-6410.

24 Y. Segawa, H. Omachi and K. Itami, Org. Lett., 2010, 12, 2262-2266.

25 S. E. Lewis, Chem. Soc. Rev., 2015, 44, 2221-2304.

26 K. Yuan, J.-S. Dang, Y.-J. Guo and X. Zhao, J. Comput. Chem., 2015, 36, 518-528.

27 J. M. Van Raden, E. R. Darzi, L. N. Zakharov and R. Jasti, Org. Biomol. Chem., 2016, 14, 5721-5727.

28 A. von Baeyer, Ber. Dtsch. Chem. Ges., 1885, 18, 2278.

29 F. Klappenberger, Y.-Q. Zhang, J. Bjork, S. Klyatskaya, M. Ruben and J. V. Barth, Acc. Chem. Res., 2015, 48, 21402150.

30 F. H. Westheimer, Special Publication No. 8, The Chemical Society, London, 1957, p. 1.

31 T. Dudev and C. Lim, J. Am. Chem. Soc., 1998, 120, 44504458.

32 W. J. Hehre, R. Ditchfield, L. Radom and J. A. Pople, J. Am. Chem. Soc., 1970, 92, 4796-4801.

33 O. V. Dorofeeva and O. N. Ryzhova, J. Phys. Chem. A, 2016, 120, 2471-2479.
34 P. Wessig, M. Czarnecki, D. Badetko, U. Schilde and A. Kelling, J. Org. Chem., 2016, 81, 9147-9157.

35 R. V. Williams, A. G. Al-Sehemi, A. K. Meier, Z. Z. Brown and J. R. Armantrout, J. Org. Chem., 2017, 82, 4136-4147.

36 R. Notario, M. V. Roux and O. Castano, Phys. Chem. Chem. Phys., 2011, 3, 3717-3721.

37 N. Sebbar, H. Bockhorn and J. W. Bozzelli, Phys. Chem. Chem. Phys., 2002, 4, 3691-3703.

38 R. O. Ramabhadran and K. Raghavachari, Acc. Chem. Res., 2014, 47, 3596-3604.

39 S. E. Wheeler, K. N. Houk, P. R. Schleyer and W. D. Allen, J. Am. Chem. Soc., 2009, 131, 2547-2560.

40 M. A. Ali and M. S. Krishnan, J. Org. Chem., 2010, 75, 57975809.

41 P. Nava and Y. Carissan, Phys. Chem. Chem. Phys., 2014, 16, 16196-16203.

42 A. D. Becke, J. Chem. Phys., 1993, 98, 5648-5652.

43 M. J. Frisch, G. W. Trucks, H. B. Schlegel, G. E. Scuseria, M. A. Robb, J. R. Cheeseman, G. Scalmani, V. Barone, B. Mennucci and G. A. Petersson, Gaussian 09, Revision D.01, Gaussian, Inc., Wallingford CT, 2009.

44 M. J. Frisch, G. W. Trucks, H. B. Schlegel, G. E. Scuseria, M. A. Robb, J. R. Cheeseman, G. Scalmani, V. Barone, B. Mennucci and G. A. Petersson, Gaussian 09, Revision E.01, Gaussian, Inc., Wallingford CT, 2009.

45 M. Moral, A. Pérez-Guardiola, E. San-Fabián, A. J. PérezJiménez and J. C. Sancho-García, J. Phys. Chem. C, 2016, 120, 22069-22078.

46 M. R. Golder, C. E. Colwell, B. M. Wong, L. N. Zakharov, J. Zhen and R. Jasti, J. Am. Chem. Soc., 2016, 138, 6577-6582.

47 D. Vijay, E. Varathan and V. Subramanian, J. Mater. Chem. A, 2013, 1, 4358-4369.

48 M. A. Ali and S. Sen, Thermochim. Acta, 2017, 654, 146-156. 49 L. A. Curtiss, P. C. Redfern and K. Raghavachari, J. Chem. Phys., 2007, 126, 084108.

50 J. A. Bouwstra, A. Schouten and J. Kroon, Acta Crystallogr., Sect. C: Cryst. Struct. Commun., 1983, 39, 1121-1123.

51 Y. Segawa, A. Fukazawa, S. Matsuura, H. Omachi, S. Yamaguchi, S. Irle and K. Itami, Org. Biomol. Chem., 2012, 10, 5979-5984.

52 T. Iwamoto, Y. Watanabe, Y. Sakamoto, T. Suzuki and S. Yamago, J. Am. Chem. Soc., 2011, 133, 8354-8361.

53 E. Kayahara, V. K. Patel and S. Yamago, J. Am. Chem. Soc., 2014, 136, 2284-2287.

54 H. Y. Afeefy, J. F. Liebman and S. E. Stein, MD, 2017, http:// webbook.nist.gov, retrieved 03.28.2017.

55 M. H. Matus, A. J. Arduengo III and D. A. Dixon, J. Phys. Chem. A, 2006, 110, 10116-10121.

56 Y. Zhao and D. G. Truhlar, J. Am. Chem. Soc., 2007, 129, 84408442 .

57 S. M. Bachrach and Z. C. Zayat, J. Org. Chem., 2016, 81, 45594565.

58 S. Lee, E. Chénard, D. L. Gray and J. S. Moore, J. Am. Chem. Soc., 2016, 138, 13814-13817.

59 C. Shen, P. Wang and M. Lu, J. Phys. Chem. A, 2015, 119, 8250-8255. 